SECTION 31. Economic research, finance, innovation.

Gennady Vasilyevich Kovalenko Associate Professor, Ph.D., St.Petersburg State Polytechnical University, Russia e-mail: $\underline{7525268 @ \text { gmail.com }}$

Michail Aleksandrovich Konovalov Head of IT department JSC "RIRT", Russia e-mail: konovalov.m@gmail.com

\title{
PRACTICAL ISSUES OF CALCULATING THE EFFICIENCY OF COMPUTER ENGINEERING SYSTEMS IN THE DESIGN OF EQUIPMENT FOR POSITIONING, NAVIGATION AND TIMING SUPPORT
}

\begin{abstract}
The problem of the effectiveness of computer systems engineering in the design of equipment for Positioning, Navigation and Timing support is considered from engineering and economic perspectives. The detailed calculation of cost-effectiveness of such a system based on real data is presented. Conclusions are based on the obtained results and a number of factors that could significantly affect the effectiveness of such systems are highlighted.

Key words: computer engineering systems, efficiency, equipment design, positioning, navigation and timing support.

\section{ПРАКТИЧЕСКИЕ ВОПРОСЫ РАСЧЕТА ЭФФЕКТИВНОСТИ ПРИМЕНЕНИЯ СИСТЕМ КОМПЬЮТЕРНОГО ИНЖИНИРИНГА ПРИ ПРОЕКТИРОВАНИИ АППАРАТУРЫ КООРДИНАТНО-ВРЕМЕННОГО И НАВИГАЦИОННОГО ОБЕСПЕЧЕНИЯ}

Аннотация: Проблема эффективности применения систем компьютерного инжиниринга при проектировании аппаратуры координатно-временного обеспечения рассматривается $c$ инженерно-технической $u$ экономической точек зрения. Приводится детальный расчет экономической эффективности такой системы на примере реальных данных. Делаются выводы по результатам расчетов и отмечаются ряд факторов, способных значительно повлиять на эффективность применения таких систем.

Ключевые слова: системь компьютерного инжиниринга, эффективность, проектирование аппаратуры, координатно-временное и навигационное обеспечение.

В работе [1] было показано, что эффективность применения систем компьютерного инжиниринга (СКИ) зависит от совокупности риск-факторов, а проблема оценки эффективности инвестирования в СКИ в России заключается не только в отсутствии «четко проработанных» методик расчета ее эффективности. Кроме того, при оценке возможности использования СКИ в проектно-конструкторской деятельности часто не в полной мере учитывается ряд ключевых инженернотехнических требований инфраструктурного характера.

Во-первых, поскольку процесс проектирования аппаратуры координатновременного и навигационного обеспечения (КВНО) обычно ведется в рамках единой информационной среды R\&D-организации [2], то для скорейшего проведения расчетов в СКИ должна быть обеспечена возможность получения данных напрямую из систем автоматизированного проектирования, используемых в процессе создания аппаратуры 
KBHО. Импорт ранее разработанных конструкторскими подразделениями R\&Dорганизации 3D моделей изделий [3] должен исключить повторный ввод данных, вести расчеты на базе единой информационной модели изделия, снизить вероятность появления ошибок «человеческого фактора» за счет автоматизации процедур трансляции данных и в конечном итоге сократить время, затрачиваемое на подготовку к расчетам. Возможность же передать в информационную систему результаты исследования является гарантией того, что эти результаты будут сохранены, станут доступны сотрудникам R\&D-организации (с учетом прав доступа) и могут быть использованы на других стадиях проектирования и жизненного цикла разрабатываемого изделия.

Во-вторых, современные СКИ содержат в себе огромное количество функций и параметров. Без наличия логичного, четко структурированного, эргономичного интерфейса у СКИ велика вероятность, что большая часть возможностей системы окажется незадействованной или же эффективность работы инженера-оператора такой системы будет недостаточно высокой.

В-третьих, у разработчиков должна присутствовать уверенность в точностных характеристиках СКИ, которые, как правило, подтверждаются, как минимум, несколькими основными путями:

- сверкой результатов решения базовых («классических») инженерных задач аналитически и с применением СКИ [4];

- сверкой результатов расчетов «эталонной» задачи: т.е. в СКИ проводится расчет некой задачи, затем этаже задача решается путем натурного эксперимента. Результаты сравниваются и делается вывод о качестве расчетов СКИ. Как правило, в роли такой задачи выступает какое-либо показательное для данной области промышленности/исследований изделие [5];

- сертификацией СКИ $[6,7,8]$

- рыночной долей продукта - многие пользователи стремятся использовать «best-in-class» продукты [9], соответственно успех продуктов, созданных с применением определенной СКИ, может косвенно служить подтверждением инженерно-технических характеристик СКИ.

В-четвертых, полученные в ходе расчетов с применением СКИ результаты расчетов не являются ценностью сами по себе, ценность появляется только после их анализа, осмысления и утверждения. Поэтому наличие в СКИ развитых средств анализа результатов расчетов и оформления, желательно автоматизированного, в типовые отчетные формы является необходимым условием эффективности ее применения.

Выполнение вышеперечисленных требований не является достаточным условием эффективности СКИ. Необходимым условием для проведения корректной оценки эффективности применения СКИ, в частности экономической эффективности, является понимание инициаторами проектов внедрения СКИ ситуации с внутренними бизнес-процессами организации-разработчика (R\&D-организации), корректно отражающими как ее деловую активность «без внедренного проекта СКИ», так и ее изменение «с внедренным проектом СКИ». К сожалению, по разным причинам, инициаторы проектов часто не обладают достаточными возможностями, чтобы развернуто описать эти процессы и выразить их в перечне начальных допущений, вводных и исходных данных, требующихся для расчета экономической эффективности.

Полезных для инициаторов проектов внедрения СКИ материалов о практиках проведения расчетов эффективности применения СКИ мало, поэтому авторы решили поделиться своим опытом решения практических вопросов, возникающих при оценке эффективности применения СКИ для решения ряда задач, возникающих перед специалистами ОАО «РИРВ» в процессе проектирования аппаратуры КВНО. 
Базовая позиция авторов в отношении принципа расчета экономической эффективности применения СКИ была сформулирована так - экономический эффект любого проекта выражается в дополнительно получаемой прибыли. Ключевой подход при проведении расчетов заключается в определении того, насколько больше, в сопоставимые периоды, R\&D-организация будет получать, и насколько больше будет платить, в результате внедрения и использования СКИ (с учетом рисков). Такая точка зрения востребована реальной практикой (см., например, $[10,11])$ и понятна лицам, принимающим бизнес-решения.

Позиция авторов в отношении исходных данных. Для проведения экономических расчетов использовать общедоступные официальные статистические и финансово-экономические данные организации, размещенные на ее сайте [12], а в случае отсутствия (недоступности по разным причинам) необходимых данных понятные для всех заинтересованных сторон проекта допущения, сформулированные инициаторами проекта, и обоснованные предположения, основанные на суждениях специалистов, причастных к проекту.

Результаты расчетов согласно [13] априори были классифицированы как пятого класса точности.

Отправной точкой для формирования направлений затрат и эффектов внедрения системы СКИ при проектировании аппаратуры КНВО был принят конечный перечень задач инженерного анализа, предполагаемых к реализации в этой программной среде: расчет напряженно-деформируемого состояния в зоне упругих деформаций; расчет напряженно-деформируемого состояния в зоне пластических деформаций; расчет собственных частот и форм колебаний; стационарный и нестационарный теплообмен; решение связанных задач «напряженно-деформируемое состояние + тепло».

Сформулированный перечень начальных допущений и вводных для расчета экономической эффективности применения СКИ для удобства был сведен в табл. 1.

Начальные допущения и вводные для расчета эффективности СКИ

\section{Таблица 1}

\begin{tabular}{|c|c|c|c|}
\hline $\mathbf{N}$ п/ & $\begin{array}{c}\text { Исходная } \\
\text { предпосылка, } \\
\text { вводная }\end{array}$ & Значение & Комментарий \\
\hline 1 & $\begin{array}{l}\text { «Зримое» } \\
\text { воплощение проекта } \\
\text { СКИ на базе ANSYS }\end{array}$ & $\begin{array}{l}\text { Программно- } \\
\text { технический } \\
\text { комплекс (ПТК) }\end{array}$ & $\begin{array}{l}\text { В рассматриваемом примере СКИ } \\
\text { рассматривается как единый ПТК, } \\
\text { поэтому формально он, как } \\
\text { основное средство, был отнесен } \\
\text { ко второй амортизационной } \\
\text { группе. На самом деле здесь } \\
\text { возможны варианты, применение } \\
\text { которых зависит от конкретной } \\
\text { ситуации. }\end{array}$ \\
\hline 2 & $\begin{array}{l}\text { Классификация } \\
\text { проекта по месту }\end{array}$ & $\begin{array}{l}\text { Реализуется } \\
\text { действующей } \\
\text { организации }\end{array}$ & $\begin{array}{l}\text { Отсутствуют затраты "чистого } \\
\text { поля". }\end{array}$ \\
\hline 3 & $\begin{array}{l}\text { Классификация } \\
\text { изменений объемов } \\
\text { сбыта }\end{array}$ & $\begin{array}{l}\text { Рынок } \\
\text { неизменен }\end{array}$ & 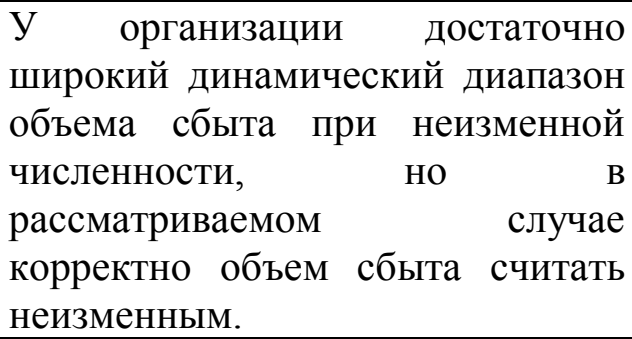 \\
\hline
\end{tabular}




\begin{tabular}{|c|c|c|c|}
\hline $\mathbf{N} \mathbf{m} / \mathbf{\Pi}$ & $\begin{array}{c}\text { Исходная } \\
\text { предпосылка, } \\
\text { вводная }\end{array}$ & Значение & Комментарий \\
\hline 4 & $\begin{array}{l}\text { Причина изменения } \\
\text { прибыли } \\
\text { организации }\end{array}$ & $\begin{array}{l}\text { Абсолютные } \\
\text { приросты } \\
\text { сокращения или } \\
\text { доходов и затрат, а } \\
\text { не их } \\
\text { перераспределение }\end{array}$ & $\begin{array}{l}\text { На сколько изменятся текущие } \\
\text { затраты организации в связи с } \\
\text { реализацией проекта, возникнут } \\
\text { ли новые, сократятся ли } \\
\text { существующие? }\end{array}$ \\
\hline 5 & $\begin{array}{l}\text { Исходная база для } \\
\text { определения } \\
\text { изменений }\end{array}$ & 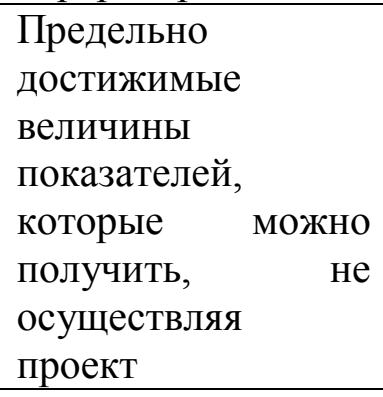 & $\begin{array}{l}\text { Если операция предусмотрена } \\
\text { нормативом, но фактически не } \\
\text { выполняется, то в качестве } \\
\text { исходной базы принимается } \\
\text { норматив. }\end{array}$ \\
\hline 6 & Группировка затрат & $\begin{array}{l}\text { Переменные } \\
\text { постоянные }\end{array}$ & $\begin{array}{l}\text { Переделывается } 1 \text { или не } \\
\text { переделывается конструкторская } \\
\text { разработка в форме опытного } \\
\text { макета - постоянные затраты на } \\
\text { весь объем производства не } \\
\text { изменяются при прочих равных } \\
\text { условиях. }\end{array}$ \\
\hline 7 & $\begin{array}{l}\text { Цена контракта на } \\
\text { поставку СКИ }\end{array}$ & $\begin{array}{l}\text { Неделимая, } \\
\text { ключ" }\end{array}$ & \begin{tabular}{lrr} 
В цене & не выделяются \\
поэлементно & составляющие, за \\
исключением & НДС. Указываются \\
юридические & \multicolumn{2}{c}{ обязательства } \\
поставщика по по каждой \\
составляющей цены.
\end{tabular} \\
\hline 8 & $\begin{array}{l}\text { Источник } \\
\text { информации для } \\
\text { расчета } \\
\text { экономических } \\
\text { показателей }\end{array}$ & Публичные данные & $\begin{array}{l}\text { Отчетность организации, } \\
\text { заверенная аудиторами. }\end{array}$ \\
\hline 9 & $\begin{array}{lr}\text { Базовый } & \text { период } \\
\text { проведения расчетов }\end{array}$ & 2012 год & $\begin{array}{l}\text { В случае отсутствия данных за } \\
2012 \text { - расчетные величины на } \\
\text { основании средних значений за } \\
\text { период 2010-2011 годов }\end{array}$ \\
\hline 10 & $\begin{array}{l}\text { Принцип } \\
\text { сопоставления } \\
\text { количественных } \\
\text { изменений }\end{array}$ & $\begin{array}{l}\text { Базовый период } \\
\text { «без проекта» и «с } \\
\text { проектом» }\end{array}$ & $\begin{array}{l}\text { В терминах формально не } \\
\text { действующей, но по-прежнему } \\
\text { актуальной и грамотной методики } \\
{[14]}\end{array}$ \\
\hline 11 & $\begin{array}{l}\text { Ставка налога на } \\
\text { имущество }\end{array}$ & $2,2 \%$ & 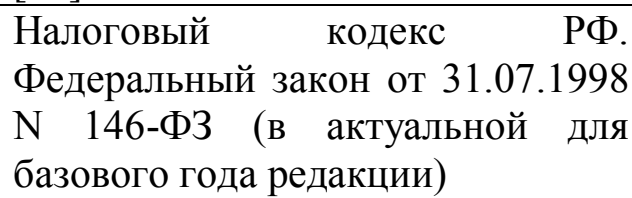 \\
\hline 14 & $\begin{array}{l}\text { Ставка налога на } \\
\text { прибыль }\end{array}$ & $20,0 \%$ & $\begin{array}{lll}\text { Налоговый } & \text { кодекс } & \text { РФ. } \\
\text { Федеральный закон от } 31.07 .1998 \\
\mathrm{~N} \quad \text { 146-Ф3 (в актуальной для } \\
\text { базового года редакции) }\end{array}$ \\
\hline
\end{tabular}


ISPC «Integration of Science \& Education», 30.03.2014

\begin{tabular}{|c|c|c|c|}
\hline $\mathbf{N}$ п/I & $\begin{array}{c}\text { Исходная } \\
\text { предпосылка, } \\
\text { вводная } \\
\end{array}$ & Значение & Комментарий \\
\hline 15 & Ставка НДС & $18,0 \%$ & 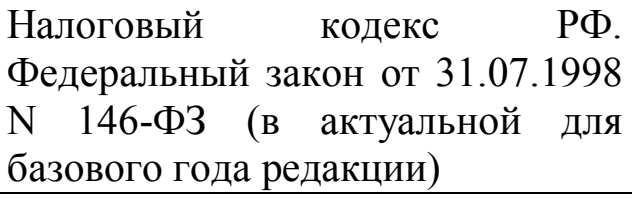 \\
\hline 16 & $\begin{array}{ll}\text { Ставка } & \text { отчислений } \\
\text { на } & \text { социальные } \\
\text { нужды } & \end{array}$ & $30,2 \%$ & $\begin{array}{l}\text { Федеральный закон от } 24.07 .2009 \\
\text { № 212-Ф3 «О страховых } \\
\text { взносах..." (в актуальной для } \\
\text { базового года редакции) }\end{array}$ \\
\hline
\end{tabular}

Далее все начальные исходные и полученные расчетным путем данные, необходимые для оценки экономической эффективности использования СКИ в ОАО «РИРВ» были сведены в табл. 2.

Таблица 2

Исходные данные для расчета эффективности СКИ

\begin{tabular}{|c|c|c|c|}
\hline $\mathrm{N}_{\mathbf{I}} / \mathbf{I}$ & Показатель & Величина & Основание \\
\hline 1 & Количество ОКР & 69 & По данным 2012 года \\
\hline 2 & $\begin{array}{l}\text { Количество наименований } \\
\text { опытных образцов на одну } \\
\text { ОКР }\end{array}$ & 1,0 & Предположение специалиста \\
\hline 3 & $\begin{array}{lrr}\text { Среднее количество } & \text { опытных } \\
\text { образцов } & \text { на } & \text { одно } \\
\text { наименование, экз. } & \end{array}$ & 4,7 & $\begin{array}{l}\text { Расчет по среднему за } \\
\text { период 2010-2011 годов }\end{array}$ \\
\hline 4 & $\begin{array}{l}\text { Базовое количество опытных } \\
\text { образцов }\end{array}$ & 324 & $\begin{array}{l}\text { Расчетная величина } \\
\text { базового периода }\end{array}$ \\
\hline 5 & 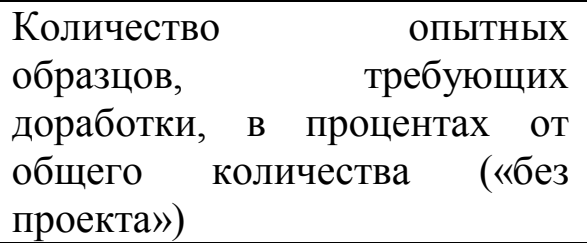 & $32 \%$ & Суждение специалиста \\
\hline 6 & 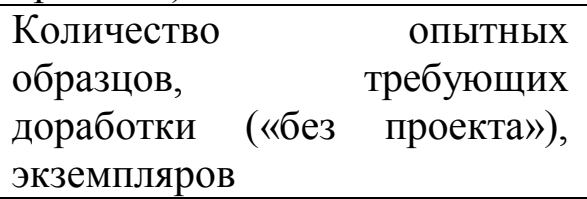 & 104 & Расчет \\
\hline 7 & 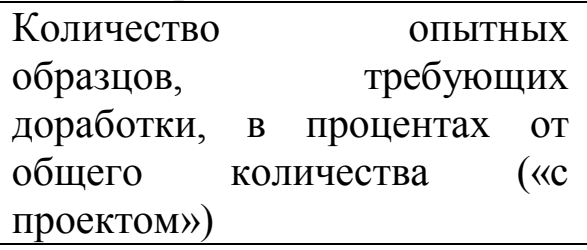 & $19 \%$ & Предположение специалиста \\
\hline 8 & 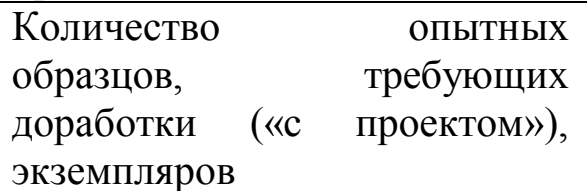 & 62 & Расчет \\
\hline 9 & $\begin{array}{lcr}\text { Расчетная } & \text { цена } & \text { одного } \\
\text { опытного образца, тыс. рублей }\end{array}$ & 2959,3 & \begin{tabular}{lcc} 
Расчет на & \multicolumn{2}{c}{ основании } \\
статистических & данных & за \\
период & $2010-2011$ годов
\end{tabular} \\
\hline
\end{tabular}




\begin{tabular}{|c|c|c|c|}
\hline $\mathbf{N} \mathbf{\Pi} / \mathbf{I}$ & Показатель & Величина & Основание \\
\hline 10 & $\begin{array}{lr}\text { Стоимость } & \text { доработки } \\
\text { опытного образца, в процентах } \\
\text { от элемента } \\
\text { затрат }\end{array}$ & $9 \%$ & Предположение специалиста \\
\hline 11 & $\begin{array}{l}\text { Цикл инженерного анализа } \\
\text { «без проекта», месяцев }\end{array}$ & 0,5 & $\begin{array}{l}\text { Суждение специалиста на } \\
\text { основе анализа внутренних } \\
\text { бизнес-процессов }\end{array}$ \\
\hline 12 & $\begin{array}{l}\text { Цикл инженерного анализа «с } \\
\text { проектом», месяцев }\end{array}$ & 0,75 & $\begin{array}{l}\text { Было принято решение } \\
\text { добавить одну неделю к } \\
\text { ситуации «без проекта» на } \\
\text { подготовку данных для } \\
\text { инженерного анализа }\end{array}$ \\
\hline 13 & $\begin{array}{lr}\text { Фонд оплаты } & \text { труда } \\
\text { сотрудников, } & \text { занятого } \\
\text { инженерным } & \text { анализом «без } \\
\text { проекта», тыс. рублей в месяц }\end{array}$ & 60 & Предположение специалиста \\
\hline 14 & $\begin{array}{l}\text { Фонд оплаты } \\
\text { сотрудников, труда } \\
\text { инженерным ананятого } \\
\begin{array}{l}\text { проектом», тыс. рублей } \\
\text { месяц }\end{array}\end{array}$ & 90 & $\begin{array}{l}\text { Расчет исходя из изменения } \\
\text { продолжительности цикла } \\
\text { инженерного анализа }\end{array}$ \\
\hline 15 & $\begin{array}{lll}\text { Срок полезного использования } \\
\text { СКИ (в форме внеоборотного } \\
\text { актива «ПТК } & \text { ANSYS»), } \\
\text { месяцев } & & \\
\end{array}$ & 36 & $\begin{array}{l}\text { Вторая } \quad \text { амортизационная } \\
\text { группа }\end{array}$ \\
\hline 16 & $\begin{array}{l}\text { Затраты на техническую } \\
\text { поддержку функционирования } \\
\text { программной части СКИ, в \% } \\
\text { от стоимости программного } \\
\text { обеспечения }\end{array}$ & $18 \%$ & $\begin{array}{l}\text { Среднее по рынку } \\
\text { предложение вендоров }\end{array}$ \\
\hline 17 & $\begin{array}{lccr}\text { Затраты } & \text { на } & \text { ремонт } & \text { и } \\
\text { обслуживание } & \text { аппаратной } \\
\text { части } & \text { СКИ, } & \% & \text { от } \\
\text { первоначальной стоимости } & \end{array}$ & $6 \%$ & $\begin{array}{l}\text { Суждение специалиста на } \\
\text { основе опыта ремонта и } \\
\text { обслуживания }\end{array}$ \\
\hline 18 & $\begin{array}{l}\text { Затраты на } \\
\text { электроэнергию }\end{array}$ & & \\
\hline 19 & $\begin{array}{l}\text { Установленная } \\
\text { мощность } \\
\text { компьютеров и } \\
\text { периферийных } \\
\text { устройств, киловатт }\end{array}$ & 1,5 & $\begin{array}{l}\text { Суждение специалиста, } \\
\text { основывающееся } \\
\text { спецификации поставки }\end{array}$ \\
\hline 20 & $\begin{array}{l}\text { Среднее число часов } \\
\text { работы компьютеров и } \\
\text { периферийных } \\
\text { устройств в один } \\
\text { рабочий день }\end{array}$ & 9 & Предположение специалиста \\
\hline 21 & $\begin{array}{l}\text { Количество рабочих } \\
\text { дней в году }\end{array}$ & 249 & $\begin{array}{l}\text { Рабочий календарь для } 2012 \\
\text { года }\end{array}$ \\
\hline 22 & Стоимость квт-час & 2,77 & Оценка по среднему на \\
\hline
\end{tabular}


ISPC «Integration of Science \& Education», 30.03.2014

\begin{tabular}{|c|c|c|l|}
\hline $\mathbf{N}$ п/п & Показатель & Величина & \multicolumn{1}{c|}{ Основание } \\
\hline & электроэнергии, рублей & & $\begin{array}{l}\text { основании данных годового } \\
\text { отчета за 2012 год }\end{array}$ \\
\hline
\end{tabular}

Относительно пункта 18 табл. 2 хотелось бы отметить, что в современных российских реалиях учет затрат на электроэнергию в контексте проведения, по сути, математических расчетов, выглядит несколько натянуто-конъюнктурным, однако он принципиально необходим для обеспечения возможности более корректно сравнивать полученные результаты с зарубежным опытом. В лучших практиках за рубежом энергоэффективности математических расчетов уделяется достаточно много внимания, поскольку в их реалиях стоимость электроэнергии, объемы ее потребления, количество расчетов и их экономический эффект достаточно тесно связаны [15].

Затем была определена структура затрат в разрезе экономических элементов в расчете на одно опытное изделие (табл. 3). Это позволило при прочих равных условиях избежать влияния перераспределительных отношений при формировании затрат на итоговую оценку, что неизбежно, если в качестве исходных используются данные о калькуляции себестоимости изделия по статьям затрат.

Таблица 3

Структура затрат в разрезе экономических элементов

\begin{tabular}{|l|c|c|}
\hline \multicolumn{1}{|c|}{ Элементы затрат } & $\begin{array}{c}\text { Сумма, } \\
\text { тыс. рублей* }\end{array}$ & Структура, \% (расчетно) \\
\hline Материальные затраты & 736556 & 44,0 \\
\hline Расходы на оплату труда & 582441 & 34,8 \\
\hline Отчисления на социальные нужды & 146351 & 8,7 \\
\hline Амортизация & 95973 & 5,7 \\
\hline Прочие затраты & 114032 & 6,8 \\
\hline Итого & 1675353 & 100,0 \\
\hline
\end{tabular}

*по данным бухгалтерской отчетности за 2012 год

Исходя из расчетной цены опытного макета (без НДС) и величины затрат в 95 копеек в расчете на 1 рубль продаж согласно данным бухгалтерской отчетности 2012 года ОАО «РИРВ» были получены величины расчетных затрат в поэлементном разрезе в пересчете на одно опытное изделие (Табл. 4).

Таблица 4

Развертка затрат по элементам на одно опытное изделие, тыс. рублей

\begin{tabular}{|l|c|c|}
\hline \multicolumn{1}{|c|}{ Элемент затрат } & Сумма, тыс. рублей & $\begin{array}{c}\text { Категория } \\
\text { затрат }\end{array}$ \\
\hline Материальные затраты & 1236,7 & Переменные \\
\hline Расходы на оплату труда & 977,9 & Переменные \\
\hline Отчисления на социальные нужды & 245,7 & Переменные \\
\hline Амортизация & 161,1 & Постоянные \\
\hline Прочие затраты & 191,5 & Постоянные \\
\hline Итого & 2812,9 & \\
\hline
\end{tabular}


Величина затрат на приобретение и развертывание СКИ была рассчитана исходя из перечня статей, приведенных в табл. 5.

Таблица 5

Оценка затрат на приобретение и развертывание СКИ

\begin{tabular}{|c|c|c|c|}
\hline $\begin{array}{c}\mathbf{N} \\
\Pi / \mathbf{I}\end{array}$ & Статьи затрат & $\begin{array}{l}\text { Сумма, тыс. } \\
\text { рублей }\end{array}$ & Основание \\
\hline 1 & $\begin{array}{ll}\text { Стоимость } & \text { программной } \\
\text { составляющей СКИ (ANSYS) }\end{array}$ & 2600,0 & Запрос поставщику \\
\hline 2 & $\begin{array}{ll}\text { Стоимость } & \text { аппаратной } \\
\text { составляющей СКИ } & \\
\end{array}$ & 500,0 & Запрос поставщику \\
\hline 3 & Обучение персонала & 350,0 & Запрос поставщику \\
\hline 4 & Пуско-наладочные работы & 100,0 & Запрос поставщику \\
\hline 5 & 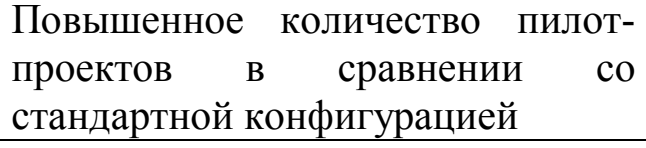 & 100,0 & $\begin{array}{l}\text { Результат риск-анализа, } \\
\text { выполненного по методике, } \\
\text { изложенной в [15]. }\end{array}$ \\
\hline 6 & Итого стоимость СКИ с НДС & 3650,0 & \\
\hline 7 & Итого стоимость СКИ без НДС & 3093,2 & \\
\hline
\end{tabular}

Величины переменных затрат на единицу опытного изделия «без проекта» для наглядности были сведены отдельно в табл. 6, так как для ситуации «с проектом» предполагалось, что они уменьшаются на «стоимость доработки опытного образца» (пункт 10 табл. 2) для тех опытных образцов, которые в результате применения СКИ не пришлось дорабатывать.

Таблица 6

Переменные затраты на единицу опытного изделия

\begin{tabular}{|l|c|c|}
\hline \multicolumn{1}{|c|}{ Переменные затраты } & $\begin{array}{c}\text { Переменные затраты на } \\
\text { единицу опытного изделия, } \\
\text { тыс. рублей }\end{array}$ & Основание \\
\hline Материальные затраты & 1236,7 & Табл.4 \\
\hline Расходы на оплату труда & 977,9 & Табл.4 \\
\hline Отчисления на социальные нужды & 245,7 & Табл.4 \\
\hline
\end{tabular}

Величины постоянных затрат в расчете на базовое количество опытных изделий за год «без проекта» и изменений «с проектом» представлены в табл. 7. Причина изменения уровня постоянных затрат - использование более квалифицированного и интенсивного труда, ввод в действие СКИ как нового внеоборотного актива.

Таблица 7

Изменение постоянных затрат

\begin{tabular}{|c|c|c|c|}
\hline $\begin{array}{c}\mathbf{N} \\
\Pi / \Pi\end{array}$ & $\begin{array}{c}\text { Постоянные затраты в } \\
\text { расчете на базовое } \\
\text { количество опытных } \\
\text { макетов за год }\end{array}$ & $\begin{array}{c}\text { Абсолютные } \\
\text { значения за } \\
\text { период, тыс. } \\
\text { рублей }\end{array}$ & Основание \\
\hline
\end{tabular}


ISPC «Integration of Science \& Education», 30.03.2014

\begin{tabular}{|c|c|c|c|}
\hline $\begin{array}{c}\mathbf{N} \\
\Pi \Pi / \Pi\end{array}$ & $\begin{array}{c}\text { Постоянные затраты в } \\
\text { расчете на базовое } \\
\text { количество опытных } \\
\text { макетов за год }\end{array}$ & $\begin{array}{c}\text { Абсолютные } \\
\text { значения за } \\
\text { период, тыс. } \\
\text { рублей }\end{array}$ & Основание \\
\hline 1 & $\begin{array}{l}\text { Амортизация } \\
\text { проекта» }\end{array}$ & 52208,6 & $\begin{array}{l}\text { Расчетно по данным табл. } 2 \text { и } \\
\text { табл.4 }\end{array}$ \\
\hline \multirow[t]{2}{*}{2} & $\begin{array}{l}\text { Прочие затраты } \text { «без } \\
\text { проекта» }\end{array}$ & 62032,6 & $\begin{array}{l}\text { Расчетно по данным табл. } 2 \text { и } \\
\text { табл.4 }\end{array}$ \\
\hline & Изменения & & Исходя из данных табл. 2 \\
\hline 3 & $\begin{array}{l}\text { Затраты на техническую } \\
\text { поддержку } \\
\text { функционирования } \\
\text { программной части СКИ }\end{array}$ & 396,6 & Рыночная практика вендоров \\
\hline 4 & $\begin{array}{l}\text { Затраты на ремонт и } \\
\text { обслуживание аппаратной } \\
\text { части СКИ }\end{array}$ & 25,4 & $\begin{array}{l}\text { Компьютеры и периферийные } \\
\text { устройства требуют внимания }\end{array}$ \\
\hline 5 & $\begin{array}{lr}\text { Затраты } & \text { на } \\
\text { электроэнергию, } & \\
\text { потребляемую СКИ } & \\
\end{array}$ & 9,3 & $\begin{array}{lr}\begin{array}{l}\text { Компьютеры и } \\
\text { устройства }\end{array} & \text { периферийные } \\
\text { электроэнергию } & \text { потребляют } \\
\end{array}$ \\
\hline \multirow[t]{3}{*}{6} & $\begin{array}{l}\text { Затраты по оплате труда } \\
\text { на инженерный анализ «с } \\
\text { проектом»: }\end{array}$ & & \\
\hline & оплата труда & 360,0 & $\begin{array}{lcc}\text { Расчетно } & \text { из предположений } \\
\text { более } & \text { интенсивном } & \text { и } \\
\text { квалифицированном труде } & \end{array}$ \\
\hline & $\begin{array}{l}\text { отчисления на } \\
\text { социальные нужды }\end{array}$ & 108,7 & $\begin{array}{l}\text { Законодательно установленная } \\
\text { величина отчислений }\end{array}$ \\
\hline 7 & Амортизация СКИ & 1031,1 & $\begin{array}{l}\text { Расчетно на основании срока } \\
\text { полезного использования }\end{array}$ \\
\hline
\end{tabular}

Рассчитав на годовом интервале изменения в разрезе переменных и постоянных затрат при переходе из ситуации «без проекта» в ситуацию «с проектом», была определена экономическая эффективность проекта внедрения и использования СКИ для решения задач инженерного анализа при проектировании аппаратуры КНВО по показателю срока окупаемости инвестиций, что представлено в табл. 8.

Таблица 8

Эффективность внедрения и использования СКИ

\begin{tabular}{|c|l|r|}
\hline $\begin{array}{c}\mathbf{N} \\
\mathbf{n} / \mathbf{I I}\end{array}$ & \multicolumn{1}{|c|}{ Изменение доходов и затрат } & $\begin{array}{c}\text { (-) } \\
\text { Сокращение, } \\
\text { (+) Рост } \\
\text { в тыс. рублей }\end{array}$ \\
\hline 1 & Изменение выручки & 0,0 \\
\hline & Изменение затрат & $-9326,5$ \\
\hline 2 & Изменение переменных затрат: & $-4688,0$ \\
\hline & Изменение материальных затрат & \multicolumn{1}{|c|}{} \\
\hline
\end{tabular}




\begin{tabular}{|c|c|c|}
\hline $\begin{array}{c}\mathbf{N} \\
\mathbf{\Pi} / \mathbf{I}\end{array}$ & Изменение доходов и затрат & $\begin{array}{c}(-) \\
\text { Сокращение, } \\
\text { (+) Рост } \\
\text { в тыс. рублей }\end{array}$ \\
\hline & Изменение расходов на оплату труда & $-3707,1$ \\
\hline & Изменение отчислений на социальные нужды & $-931,5$ \\
\hline \multirow[t]{7}{*}{3} & Изменение постоянных затрат: & 1931,1 \\
\hline & Изменение амортизации & 1031,1 \\
\hline & $\begin{array}{l}\text { Изменение затрат на техническую поддержку программной } \\
\text { части СКИ }\end{array}$ & 396,6 \\
\hline & $\begin{array}{l}\text { Изменение затрат на ремонт и обслуживание аппаратной } \\
\text { части СКИ }\end{array}$ & 25,4 \\
\hline & $\begin{array}{l}\text { Изменение затрат по оплате труда (включая социальные } \\
\text { нужды) на инженерный анализ }\end{array}$ & 468,7 \\
\hline & Изменение затрат на электроэнергию & 9,3 \\
\hline & Изменение налогов & \\
\hline 4 & Изменение налога на имущество & 68,1 \\
\hline \multirow[t]{4}{*}{5} & Изменение налога на прибыль & 1465,5 \\
\hline & $\begin{array}{l}\text { Дополнительная } \\
\text { проекта }\end{array}$ & 5861,9 \\
\hline & Инвестиции* & 3650,0 \\
\hline & Окупаемость по дополнительной прибыли, месяцев & 7,5 \\
\hline
\end{tabular}

*Принята сумма денежного оттока на приобретение СКИ

Таким образом, с формальной точки зрения применение СКИ в низкорентабельной R\&D-организации для целей инженерного анализа задач, возникающих при проектировании аппаратуры КНВО экономически эффективно срок окупаемости менее года при снижении процента опытных образцов, требующих доработки с имеющихся $32 \%$ до предполагаемых 19\%, то есть разница в $13 \%$. На практике величина этой разницы будет зависеть от таких ключевых инженернотехнических и человеческих факторов как:

- полноты обеспечения библиотеками материалов, имеющих необходимые, для выбранных классов исследуемых задач, и адекватные реальным физические параметры, с целью обеспечения необходимой точности расчетов. Отсутствие таких библиотек крайне негативно сказываются как на конечной точности расчетов, так и на самой возможности проведения таких расчетов;

- создания/актуализации и четкого выполнения регламентов применения СКИ для целей инженерного анализа;

- полноты решения вопросов интеграции и импорта первичных данных из информационных систем, существующих на предприятии, экспорт в информационные системы результатов инженерных расчетов;

- степени освоения пользователями СКИ инструментария по анализу полученных данных и построению отчетов;

- наличия достаточного количества специалистов, имеющих как сильную физикоматематическую фундаментальную подготовку, так и уверенно владеющими СКИ. 
Такие специалисты не только дорого стоят, но и их просто очень мало на рынке труда.

В завершении хотелось бы отметить, что в данной статье достаточно подробно расписана методика оценки экономической эффективности применения СКИ. Это было сделано, в том числе, с целью обеспечения заинтересованных лиц, особенно инициаторов проектов использования СКИ в конструкторской деятельности, возможностью повторить приведенные расчеты на своих наборах данных, что в последующем дало бы возможность заинтересованным лицам обмениваться опытом и оценивать эффективность применения СКИ, отталкиваясь от некой общей базы.

\section{References:}

1. Коваленко, Г.В.; Коновалов, М.А. К вопросу оценки эффективности инвестиций в системы компьютерного инжиниринга // Theoretical\&Applied Science, 2013, № 12 (8), C. 105-108.

2. Коновалов М.А.; Осипов О.Д. Переход от «информационной мозаики» к интегрированной системе предприятия / Материалы конференции «Компьютерные технологии сопровождения и поддержки наукоемкой продукции на всех этапах жизненного цикла», НИЦ CALS-технологий «Прикладная логистика», 2001 г., с.5759

3. Коновалов М.А.; Осипов О.Д. Цифровой прототип изделия, как основа создания инновационной радионавигационной аппаратуры Научно-технический семинар «Научно-технические проблемы в промышленности: интегрированные системы автоматизированного проектирования нового поколения для разработки инновационной радиоэлектронной продукции, аппаратуры и систем», материалы семинара, Санкт-Петербургская ассоциация предприятий радиоэлектроники, приборостроения, средств связи и телекоммуникаций / Авангард - СПб, 2010 г. c. $75-83$

4. Суренский Е. А.; Байчиков Ю. Д. Верификация программного комплекса ANSYS. Задачи механики разрушения // Вопросы атомной науки и техники. серия: обеспечение безопасности АЭС, 2010, № 26, С. 48-57.

5. Кузнецов Е.С. Особенности расчета ячеек электронной аппаратуры в СAПР ANSYS при случайном вибрационном воздействии // Проектирование и технология электронных средств, 2010, № 2, С. 14-16.

6. Dimitri Tselepidakis ANSYS Quality Assurance \& ASME V\&V Standards - Режим доступа:

http://www.google.ru/url?sa=t\&rct=j\&q=\&esrc=s\&source=web\&cd=1\&cad=rja\&uact=8

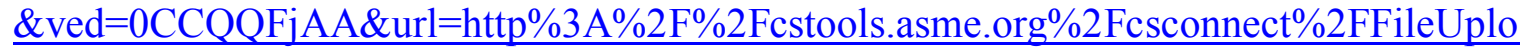
ad.cfm\%3FView\%3Dyes\%26ID\%3D39549\&ei=Y9AaU8e-

Eofn4gSlr4HQAQ\&usg=AFQjCNFeRCjLeJPGltKiGb7ZTTr5aeFwtQ - _ Дата обращения: 08.03.2014.

7. Сертификаты ANSYS - Режим доступа: http://www.delcamural.ru/cae/konstruktsionnyy analiz/ansys 0 - Дата обращения: 08.03.2014.

8. Сертификат одобрения программного средства ANSYS Structural - Режим доступа: http://www.cadfem-cis.ru/about/certif/ - Дата обращения: 08.03.2014.

9. Компьютерный инжиниринг / Боровков А.И. и др. СПб: Изд-во СПбГПУ, 2012. - 93 c.

10. Кольцова, И.В.; Рябых Д.А. Практика финансовой диагностики и оценки проектов. - М: Вильямс, 2007. - 416 с.

11. Коваленко Г.В., Самарская М.В., Фонкац А.Г. // Практические вопросы оценки состоятельности инвестиционных проектов // Лизинг, 2010, № 8. С. 13-18. 
12. ОАО «РИРВ». Раскрытие информации. - Режим доступа: http://www.rirt.ru/report Дата обращения: 20.12.2013.

13. AACE International Recommended Practice No. 18R-97 Cost estimate classification system - as applied in engineering, procurement, and construction for the process industries TCM Framework: 7.3 - AACE Inc., February 2, 2005. P.2

14. Методические рекомендации по оценке эффективности инвестиционных проектов (Вторая редакция, исправленная и дополненная) (утв. Минэкономики РФ, Минфином РФ и Госстроем РФ от 21 июня 1999 г. N ВК 477)

15. Экономика ЦОД - Режим доступа: http://www.rvip.ru/1065/document1071.shtml Дата обращения: 01.03.2014.

16. Коваленко Г.В. Управление рисками нововведений. - СПб.: Изд-во Политехн. унта, 2011. - $144 \mathrm{c}$. 